Check for updates

Cite this: RSC Adv., 2019, 9, 29010

\title{
5-Carboxylcytosine is resistant towards phosphodiesterase I digestion: implications for epigenetic modification quantification by mass spectrometry $\dagger$
}

\author{
Fang Yuan, (D) ab Ying Bi, (D) a Jia-Yuan Zhang, (D) ac Ying-Lin Zhou, (DD ${ }^{\mathrm{b}}$ \\ Xin-Xiang Zhang ${ }^{* b}$ and Chun-Xiao Song (D) *a
}

\begin{abstract}
DNA cytosine modifications are important epigenetic modifications in gene regulation and pathogenesis. DNA hydrolysis followed by HPLC-MS/MS is the gold standard in DNA modification quantification. In particular, it is the only sensitive and accurate method for low abundance modifications, such as 5carboxylcytosine $(5 \mathrm{caC})$. Here, we report the discovery of the nuclease resistance property of $5 \mathrm{caC}$ to snake venom phosphodiesterase I (PDE1), a $3^{\prime}$ to $5^{\prime}$ exonuclease commonly used in several DNA hydrolysis protocols. We conducted a systematic evaluation of six commonly used hydrolysis protocols and found that all protocols that use PDE1 underestimate the level of $5 \mathrm{caC}$. Finally, we identified the best method for cytosine modification quantification of biological samples, which leads to an over 10 -fold higher amount of $5 \mathrm{caC}$ being detected compared with other methods. Our results highlight that caution should be taken when choosing a DNA hydrolysis protocol to quantify certain DNA modifications.
\end{abstract}

Received 11th June 2019

Accepted 8th September 2019

DOI: $10.1039 / c 9 r a 04375 f$

rsc.li/rsc-advances chromatography coupled with tandem mass spectrometry (HPLC-MS/MS) is an important and widely used technology in epigenetics, and also the gold standard for accurately detecting and quantifying the overall level of DNA modifications. ${ }^{13,14}$ In fact, it is the only method sensitive enough to quantify $5 \mathrm{caC}$, the scarcest cytosine modification in the mammalian genome with only several parts per million compared to unmodified cytosine. ${ }^{4,12}$ In order to perform HPLC-MS/MS analysis, DNA samples first need to be hydrolysed to single nucleosides. The traditional DNA hydrolysis approach is the nuclease P1 protocol developed by Crain et al. ${ }^{15}$ The abundance of several important DNA/RNA modifications was determined by HPLC-MS/MS using this protocol. ${ }^{16-18}$ However, this two-step trio-enzymatic digestion method is complex and time-consuming. For example, DNA must be denatured first and the $\mathrm{pH}$ of the aqueous solution needs to be adjusted twice. Eoin and Jesse later developed a simple protocol for hydrolysing DNA, which only needs one step of incubation. In this protocol, Benzonase, a commercially available endo-nuclease was used instead of P1 nuclease. ${ }^{19} \mathrm{All}$ of the three enzymes used in this protocol can work together under the same pH condition and DNA does not have to be denatured first. This new one-step Benzonase protocol saves much time compared with the nuclease P1 protocol, and has become a popular choice since its publication., ${ }^{3,20,21}$ Another one-step protocol used DNase I instead of P1 nuclease or Benzonase. ${ }^{4}$ More recently, commercial enzymatic mixtures have also become available for one-step DNA digestion, albeit at a higher cost. 
Our group has been using the simple and low cost Benzonase protocol in the HPLC-MS/MS quantification of DNA cytosine modifications. However, when we recently employed this protocol on a 5caC-containing synthesized oligonucleotide (ODN), we found that the $5 \mathrm{caC}$ level was two to three orders of magnitude lower than expected. On the other hand, the quantification result of $5 \mathrm{caC} 2^{\prime}$-deoxynucleoside standard solution treated with Benzonase protocol was consistent with the actual concentration. This phenomenon indicates that the Benzonase protocol has an unusual effect on hydrolysing 5 caC-containing DNA.

This unexpected finding prompted us to conduct a systematic investigation of the Benzonase protocol together with five other commonly used DNA hydrolysis protocols, including two commercial products, for HPLC-MS/MS analysis of DNA cytosine modifications in the present study. MALDI-TOF analysis was also used in order to conduct a mechanistic study on the hydrolysis efficiency of target enzyme. Finally, in order to help researchers choose a suitable hydrolysis method for MS quantification of cytosine modifications, we investigated the performance of all existing protocols on hydrolysing genomic DNA from cell lines that contain variable levels of the four cytosine modifications.

First, to verify the loss of 5caC signal during the HPLC-MS/ MS analysis, we employed six commonly used hydrolysis protocols, including the Benzonase protocol, to hydrolyse two short ODNs containing either $5 \mathrm{fC}$ or $5 \mathrm{caC}$ (Table 1 and Fig. 1A). The hydrolysed products were analysed by HPLC-MS/MS. The result showed that, while DNase I/PDE1 and P1-treated samples showed lower $5 \mathrm{fC}$ levels $(69.4 \%$ and $57.8 \%$ compared with DNA Degradase Plus treated sample), the 5fC-containing ODN treated by other hydrolysis protocols shared similar $5 \mathrm{fC}$ levels, indicating that different digestion protocols in general have little effect on the hydrolysis of 5fC-containing ODN (Fig. 1B). However, the $5 \mathrm{caC}$ levels differed dramatically in 5caCcontaining ODN samples treated with different protocols (Fig. 1C). The DNA Degradase Plus protocol and NEB Digestion Mix gave the highest $5 \mathrm{caC}$ level, while no $5 \mathrm{caC}$ signal was detected in the samples treated with the PDE1 or Benzonase/ PDE1 protocol. The $5 \mathrm{caC}$ level was also lower in the DNase I/ PDE1 and P1-treated samples, but unlike $5 \mathrm{fC}$ results, DNase I/ PDE1-treated sample gave much lower 5caC level (27.6\%) compared with P1 (43.9\%). This result showed that several hydrolysis protocols caused apparent $5 \mathrm{caC}$ loss in the HPLCMS/MS analysis.

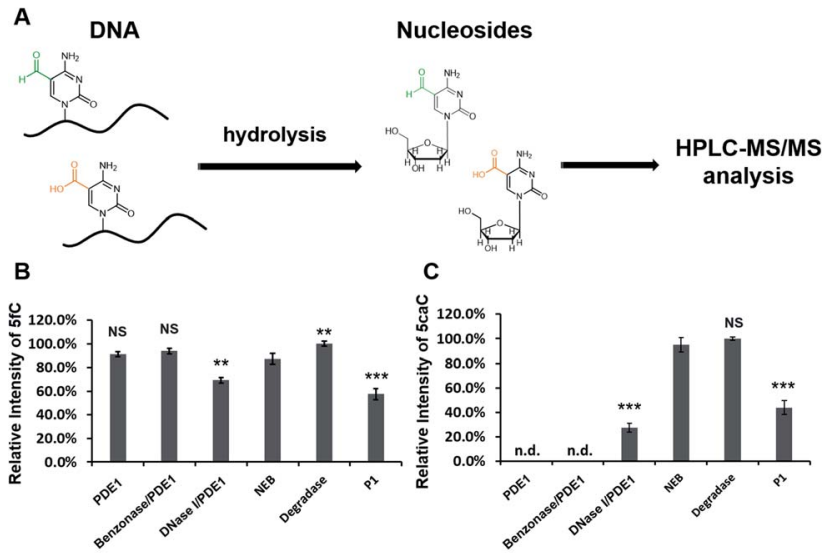

Fig. 1 The discovery of $5 \mathrm{caC}$ peak loss during the HPLC-MS/MS analysis of $5 \mathrm{caC}$-containing oligonucleotide using certain DNA hydrolysis protocols. (A) Workflow: ODNs containing either 5-formylcytosine $(5 \mathrm{fC})$ or 5 -carboxylcytosine $(5 \mathrm{caC})$ were first hydrolyzed into nucleosides with different hydrolysis protocols, and then subjected to HPLC-MS/MS analysis. (B) $5 f C$ level were similar among samples treated with PDE1, Benzonase/PDE1, NEB and Degradase hydrolysis methods $(N=3)$. (C) Obvious peak loss of $5 \mathrm{caC}$ was observed in the PDE1, Benzonase/PDE1 and DNase I/PDE1 protocols treated samples. n.d. not detectable; error bars show SD $(n=3) ; P$ value of Dunnett's multiple comparison test comparing NEB Digestion Mix with other methods. $* * P<0.01$; $* * * P<0.001$; NS, insignificant.

An aqueous solution of $5 \mathrm{caC} 2$-deoxynucleoside with a known concentration was used as control sample. After treated with the same six enzymatic digestion protocols, the $5 \mathrm{caC} 2$ '-deoxynucleoside was analysed by HPLC-MS/MS. Except for DNase I/PDE1 group, the intensities of the $5 \mathrm{caC}$ peaks were similar among untreated and other methods treated nucleosides, showing that enzyme treatments do not affect the ability to detect $5 \mathrm{caC}$ single nucleosides (Fig. S1†). Based on these results, we propose that, the loss of $5 \mathrm{caC}$ signal in HPLC-MS/MS analysis using these hydrolysis protocols is due to the incomplete digestion of $5 \mathrm{caC}$-containing ODN fragments, and therefore could severely influence the quantification of $5 \mathrm{caC}$ in DNA samples.

One common enzyme used in the protocols that resulted in $5 \mathrm{caC}$ signal loss is the $3^{\prime}$ to $5^{\prime}$ exonuclease PDE1 (Table 1 ). The $3^{\prime}$ to $5^{\prime}$ exonuclease activity of PDE1 was first found in $1959,{ }^{22}$ and has been widely used to hydrolyse DNA samples since then., ${ }^{4,19}$ Certain lesions of DNA, such as apurinic (AP) sites and thymine glycols $\left(\mathrm{T}^{\mathrm{g}}\right)$ are reported to be refractory to PDE1 digestion. ${ }^{23,24}$

Table 1 Different hydrolysis methods investigated in this work

\begin{tabular}{lllr}
\hline Hydrolysis methods & Name & Enzyme & Time \\
\hline One-step & PDE1 & PDE1, ALP & Temp. $\left({ }^{\circ} \mathrm{C}\right)$ \\
& Benzonase/PDE1 & Benzonase, PDE1, ALP & 37 \\
& DNase I/PDE1 & DNase I, PDE1, ALP & 37 \\
& NEB & Nucleoside Digestion Mix (NEB) & 37 \\
& Degradase & DNA Degradase Plus (Zymo) & 37 \\
P1 & P1 nuclease, PDE1, ALP & 37 \\
& & & Step 1: overnight \\
& & & Step 2: $3 \mathrm{~h}$
\end{tabular}


Moreover, a polyamine-modified nucleoside was shown to be more resistant to PDE1 than unmodified ODNs. ${ }^{25}$ However, no studies have reported the nuclease resistance property of natural occurring DNA cytosine modifications like $5 \mathrm{caC}$. To the contrary, studies that reported undetected 5caC using HPLCMS/MS often attributed this to the extremely low abundance of this modification. ${ }^{26,27}$ In order to investigate whether $5 \mathrm{caC}$ is refractory to exonucleases like PDE1, we used an 11-mer caCcontaining ODN as a model, and analysed the hydrolysed products of this model using MALDI-TOF after treatment with different enzymatic digestion protocols (Fig. 2A). The original ODN had one peak at $m / z=3366.0$ (Fig. 2B), while DNA Degradase Plus-treated ODN showed no peak (Fig. 2C), indicating the complete digestion of the ODN. A new peak with $\mathrm{m} / \mathrm{z}$ $=1802.1$ was observed in both PDE1-treated ODN and Benzonase/PDE1-treated ODN (Fig. 2D and E), corresponding to the short fragment of this ODN ending with 5caC (5'-TCGAC5caC-3'), which demonstrated that, mechanistically, 5 caC could block the $3^{\prime}$ to $5^{\prime}$ exonuclease activity of PDE1 digestion right at the modification position.

The time-dependent PDE1 resistance of 5caC to digestion was also investigated using the 5caC-containing ODN model. As shown in Fig. S2, $\dagger$ protocols that use the NEB Nucleoside, Digestion Mix or DNA Degradase Plus (Zymo) can digest target 5 caC ODN completely in $2 \mathrm{~h}$. However, protocols using Benzonase/PDE1 or PDE1 digested less than $20 \%$ of the ODN substrate even after $24 \mathrm{~h}$ of incubation, confirming the resistance of $5 \mathrm{caC}$ to PDE1 digestion.

Global quantification of one nucleoside modification can indicate its potential role in the biological system and is crucial data to guide subsequent sequencing and biological experiments. It is extremely important to choose a suitable hydrolysis

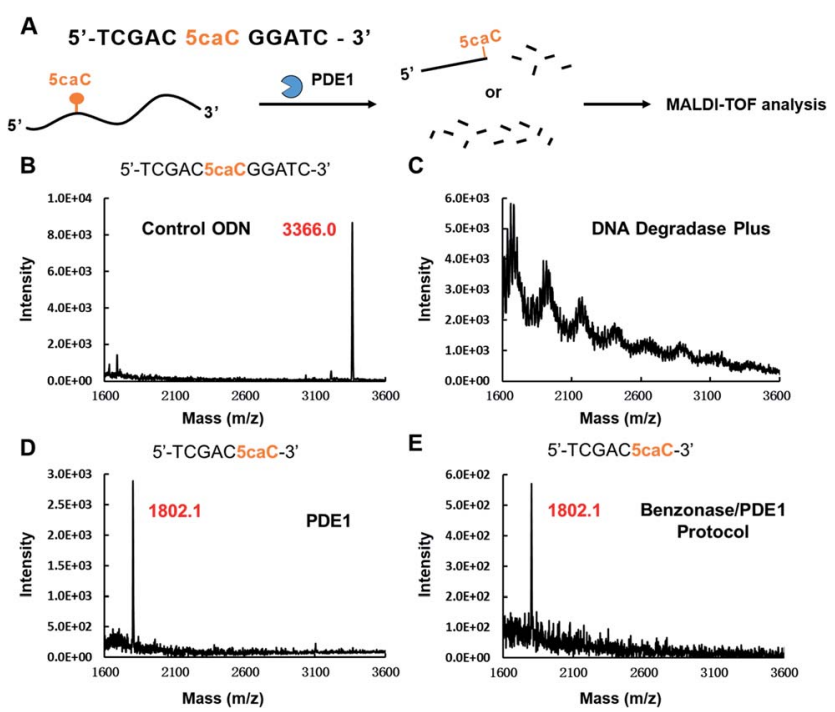

Fig. 2 (A) Scheme of using MALDI-TOF to investigate whether $5 \mathrm{caC}$ is refractory to exonucleases like PDE1. Results of (B) control $5 \mathrm{caC}$ containing ODN, (C) DNA Degradase Plus treated ODN, (D) PDE1 protocol treated ODN and (E) Benzonase/PDE1 protocol treated ODN revealed that $5 \mathrm{caC}$-containing ODN is resistant to PDE1 exonuclease hydrolysis. method that can fully digest the DNA sample in an unbiased manner. The first paper to discover $5 \mathrm{caC}$ in the mammalian genome in 2011 used the DNase I/PDE1 protocol. ${ }^{4}$

Unlike P1 nuclease, which exhibits both exonuclease and endonuclease activity that can directly hydrolyse DNA to single nucleosides, ${ }^{28}$ Benzonase $^{29}$ and DNase $\mathrm{I}^{28}$ are both endonucleases that cleave DNA to release oligonucleotides. In order to fully digest DNA into single nucleosides, exonuclease PDE1 is added in these two hydrolysis protocols. Unfortunately, for $5 \mathrm{caC}$ substrates, our results already showed that such combined DNA hydrolysis protocols could lead to modest to severe underestimation of $5 \mathrm{caC}$ levels in synthesized ODN samples. Genomic DNA (gDNA) contains much more complicated base compositions and chemical modifications. To further demonstrate the 5 caC digestion issue in a more biologically related setting, we next tested gDNA from mTet1 catalytic domain overexpressed $293 \mathrm{~T}$ cells. Since Tet proteins can oxidize $5 \mathrm{mC}$ to $5 \mathrm{hmC}, 5 \mathrm{fC}$ and $5 \mathrm{caC}$, these three cytosine modifications are expected to exist in relatively high levels in this cell line.

The HPLC-MS/MS quantification results of each cytosine modification are shown in Fig. 3. The levels of all modifications investigated in this experiment were lower using the P1 Nuclease hydrolysis protocol than a one-step protocol like the NEB Digestion Mix, indicating that, although with the longest incubation time, this two-step hydrolysis protocol cannot fully digest gDNA. As for different one-step hydrolysis methods treated samples, the levels of $5 \mathrm{mC}$ were similar among all samples, while the level of $5 \mathrm{hmC}$ was about $20 \%$ higher in the Digestion Mix-treated sample than others. The levels of $5 \mathrm{fC}$ were similar among PDE1, Benzonase/PDE1, DNase I/PDE1 and NEB Digestion Mix-treated samples, while 20\% lower in the Degradase-treated sample. The levels of $5 \mathrm{caC}$ in this gDNA sample were strikingly different between the different hydrolysis methods. Unlike the ODN results, the NEB Digestion Mixtreated gDNA gave the highest $5 \mathrm{caC}$ level $(5 \mathrm{caC} / \mathrm{dG}$ value was

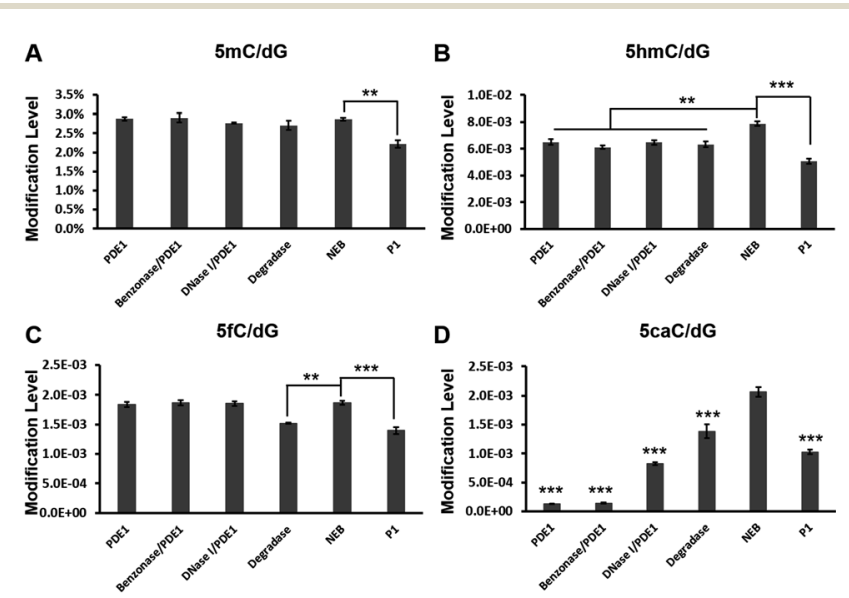

Fig. 3 HPLC-MS/MS quantification of four DNA cytosine modifications in the genomic DNA from Tet1 overexpressed 293T cells using different DNA hydrolysis protocols. (A) $5 \mathrm{mC}$, (B) $5 \mathrm{hmC}$, (C) $5 \mathrm{fC}$, (D) $5 \mathrm{caC}$. Error bars show SD $(n=3) ; P$ value of Dunnett's multiple comparison test using NEB Digestion Mix as control. ** $P<0.01 ; * * * P<$ 0.001. 
$2.06 \times 10^{-3}$ ), while the $5 \mathrm{caC} / \mathrm{dG}$ value was $1.38 \times 10^{-3}$ in the Degradase-treated sample, 33\% lower than the Digestion Mixtreated group. PDE1 and PDE1/Benzonase methods gave the lowest $5 \mathrm{caC} / \mathrm{dG}$ values $\left(1.28 \times 10^{-4}\right.$ and $1.40 \times 10^{-4} \mathrm{respec}-$ tively), indicating that only $6.2 \%$ and $6.8 \%$ of the $5 \mathrm{caC}$ modifications were digested into single nucleosides in these samples. The $5 \mathrm{caC} / \mathrm{dG}$ level in the DNase I and P1 nuclease-treated samples $\left(8.26 \times 10^{-4}\right.$, and $\left.1.03 \times 10^{-3}\right)$ were $40.0 \%$ and $49.7 \%$ of those in Digestion Mix-treated group, respectively.

Another biologically relevant sample we tested was gDNA from Tdg ${ }^{\text {flox/flox }}$ mouse embryonic stem cells (mESC) and $\mathrm{Tdg}^{-/}$

mESC. ${ }^{30}$ There are a few studies that reported the level of $5 \mathrm{caC}$ in wild-type mESC, ${ }^{\mathbf{4}, \mathbf{6}}$ while Tdg knock-out leads to increased levels of $5 \mathrm{fC}$ and $5 \mathrm{caC}$ in mESC. ${ }^{30,31}$ Since most of these works used a PDE1-containing hydrolysis enzyme mix or the two-step protocol, we wanted to investigate the influence of different hydrolysis methods on the level of $5 \mathrm{caC}$ detected.

The same amount of gDNA was used in each hydrolysis experiment. As shown in Fig. $4 \mathrm{~A}$ and $\mathrm{B}$, the levels of $5 \mathrm{hmC}$ were similar among PDE1, Benzonase/PDE1, Degradase, NEB Digestion Mix and P1-treated Tdg ${ }^{\text {flox/flox }}$ gDNA samples, and all one-step hydrolysis methods-treated $\mathrm{Tdg}^{-1-}$ gDNA samples. However, the $5 \mathrm{caC} / \mathrm{dC}$ levels in $\mathrm{Tdg}^{-1-}$ mESC treated with Degradase or NEB Digestion Mix were 6 to 10 times higher than those treated with PDE1, Benzonase/PDE1 or P1 nuclease methods (Fig. 4D). Moreover, unlike the successful quantification of $5 \mathrm{caC}$ in $\mathrm{Tdg}^{-1-}$ mESC using Degradase or NEB Digestion Mix, we could not detect any 5 caC signal in $\mathrm{Tdg}^{\text {flox/flox }}$ gDNA samples treated with the PDE1, Benzonase/PDE1 or P1 nuclease methods (Fig. 4C).

According to these results, we conclude that both the NEB Digestion Mix and DNA Degradase Plus are suitable hydrolysis methods to obtain accurate 5 caC levels in gDNA from biological samples, although the former gives more stable results in most of the cases. DNase I and P1 nuclease protocols gave acceptable
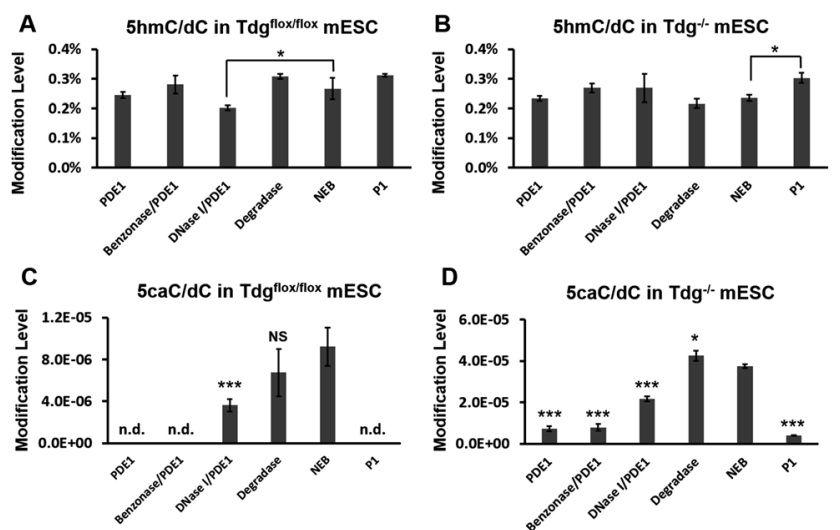

Fig. 4 HPLC-MS/MS quantification of genomic DNA of $\mathrm{Tdg}^{\text {flox/flox }}$ $\mathrm{mESC}$ and $\mathrm{Tdg}^{-/-} \mathrm{mESC}$ using different DNA hydrolysis protocols. (A) $5 \mathrm{hmC}$ in $\mathrm{Tdg}^{\text {flox/flox }} \mathrm{mESC}$, (B) $5 \mathrm{hmC}$ in $\mathrm{Tdg}^{-1-} \mathrm{mESC}$, (C) $5 \mathrm{caC}$ in $\mathrm{Tdg}^{\text {flox/flox }} \mathrm{mESC}$, (D) $5 \mathrm{caC}$ in $\mathrm{Tdg}^{-1-}$ mESC. n. d. not detectable; error bars show SD $(n=3)$; $P$ value of Dunnett's multiple comparison test using NEB Digestion Mix as control. $* P<0.05 ; * * P<0.01$; ${ }^{* * *} P<0.001$; NS, insignificant. results in high 5 caC-containing gDNA samples, while the $5 \mathrm{caC}$ level was severely underestimated in the PDE1 and Benzonase/ PDE1 protocol treated gDNA sample. Although PDE1 should be avoid in the HPLC-MS/MS quantification of 5caC, it might be useful to analyse the distribution of $5 \mathrm{caC}$ in the genome. Since the hydrolysis of DNA using PDE1 will be blocked and leave $5 \mathrm{caC}$ at the $3^{\prime}$ end, it could be developed into a sequencing method to determine the localization of the $5 \mathrm{caC}$.

In summary, we first reported the signal loss of $5 \mathrm{caC}$ during the HPLC-MS/MS quantification analysis using certain common DNA hydrolysis methods. We identified the cause to be that 5 caC is resistant to PDE1, an exonuclease used in DNA hydrolysis protocols like, Benzonase/PDE 1 and DNase I/PDE 1. Genomic DNA extracted from mTet1 catalytic domain overexpressed 293T cells and Tdg knockout mESC were used to evaluate the performance of six commonly used DNA hydrolysis protocols. Among all the protocols tested, Nucleoside Digestion Mix gave the highest $5 \mathrm{caC}$ level. Our results have strong implications to the epigenetic research that cautions should be made when choosing a DNA hydrolysis protocol to quantify certain DNA modifications not to introduce bias. Such bias could be particularly strong in low abundance modifications, including $5 \mathrm{caC}$, but also potentially other modifications, for instance, the more recently reported $\mathrm{N}^{6}$-methyladenine $\left(\mathrm{N}^{6}-\mathrm{mA}\right)$ in DNA. ${ }^{32-34}$

\section{Conflicts of interest}

There are no conflicts to declare.

\section{Acknowledgements}

We would like to acknowledge P. Spingardi, G. Berridge and B. Kessler for helping with the HPLC-MS/MS; G.-L. Xu for providing the Tdg ${ }^{\text {flox/flox }}$ mESC and $\mathrm{Tdg}^{-1-}$ mESC; F. Howe for editing the manuscript. This work was supported by the Ludwig Institute for Cancer Research. Work in the C.-X. Song lab is also supported by Cancer Research UK (C63763/A26394 and C63763/ A27122), NIHR Oxford Biomedical Research Centre, and Conrad N. Hilton Foundation. The views expressed are those of the authors and not necessarily those of the NHS, the NIHR or the Department of Health. F. Yuan and Y. Bi are supported by China Scholarship Council. J.-Y. Zhang is supported by NDM Summer Internship Programme. Funding for open access charge: The University of Oxford's Charity Open Access Fund (COAF).

\section{Notes and references}

1 R. J. Klose and A. P. Bird, Trends Biochem. Sci., 2006, 31, 8997.

2 E. Li and Y. Zhang, Cold Spring Harbor Perspect. Biol., 2014, 6, a019133.

3 S. Kriaucionis and N. Heintz, Science, 2009, 324, 929-930.

4 S. Ito, L. Shen, Q. Dai, S. C. Wu, L. B. Collins, J. A. Swenberg, C. He and Y. Zhang, Science, 2011, 333, 1300-1303. 
5 M. Tahiliani, K. P. Koh, Y. Shen, W. A. Pastor, H. Bandukwala, Y. Brudno, S. Agarwal, L. M. Iyer, D. R. Liu, L. Aravind and A. Rao, Science, 2009, 324, 930-935. 6 Y.-F. He, B.-Z. Li, Z. Li, P. Liu, Y. Wang, Q. Tang, J. Ding, Y. Jia, Z. Chen, L. Li, Y. Sun, X. Li, Q. Dai, C.-X. Song, K. Zhang, C. He and G.-L. Xu, Science, 2011, 333, 1303-1307.

7 A. Maiti and A. C. Drohat, J. Biol. Chem., 2011, 286, 3533435338.

8 M. W. Kellinger, C.-X. Song, J. Chong, X.-Y. Lu, C. He and D. Wang, Nat. Struct. Mol. Biol., 2012, 19, 831.

9 E.-A. Raiber, G. Portella, S. Martínez Cuesta, R. Hardisty, P. Murat, Z. Li, M. Iurlaro, W. Dean, J. Spindel, D. Beraldi, Z. Liu, M. A. Dawson, W. Reik and S. Balasubramanian, Nat. Chem., 2018, 10(12), 1258-1266.

10 L. Wang, Y. Zhou, L. Xu, R. Xiao, X. Lu, L. Chen, J. Chong, H. Li, C. He, X.-D. Fu and D. Wang, Nature, 2015, 523, 621. 11 P. W. Laird, Nat. Rev. Genet., 2010, 11, 191-203.

12 C.-X. Song, C. Yi and C. He, Nat. Biotechnol., 2012, 30, 1107. 13 R. Singh and P. B. Farmer, Carcinogenesis, 2006, 27, 178-196.

14 M. Munzel, D. Globisch, T. Bruckl, M. Wagner, V. Welzmiller, S. Michalakis, M. Muller, M. Biel and T. Carell, Angew. Chem., Int. Ed. Engl., 2010, 49, 5375-5377.

15 P. F. Crain, in Methods in Enzymology, Academic Press, 1990, vol. 193, pp. 782-790.

16 L. Song, S. R. James, L. Kazim and A. R. Karpf, Anal. Chem., 2005, 77, 504-510.

17 K. S. Lim, A. Jenner and B. Halliwell, Nat. Protoc., 2006, 1, 1995.

18 Z. Liu, S. Liu, Z. Xie, W. Blum, D. Perrotti, P. Paschka, R. Klisovic, J. Byrd, K. K. Chan and G. Marcucci, Nucleic Acids Res., 2007, 35, e31.

19 E. P. Quinlivan and J. F. Gregory, Anal. Biochem., 2008, 373, 383-385.

20 E. P. Quinlivan and J. F. Gregory 3rd, Nucleic Acids Res., 2008, 36, e119.

21 J. Yin, S. Chen, N. Zhang and H. Wang, ACS Appl. Mater. Interfaces, 2018, 10, 21883-21890.
22 W. E. Razzell and H. G. Khorana, J. Biol. Chem., 1959, 236, 2114-2117.

23 M. Weinfeld, K.-J. M. Soderlind and G. W. Buchko, Nucleic Acids Res., 1993, 21, 621-626.

24 K. J. Bowman, R. L. Pla, Y. Guichard, P. B. Farmer and G. D. D. Jones, Nucleic Acids Res., 2001, 29, e101.

25 T. Ito, Y. Ueno, Y. Komatsu and A. Matsuda, Nucleic Acids Res., 2003, 31, 2514-2523.

26 L. M. Wheldon, A. Abakir, Z. Ferjentsik, T. Dudnakova, S. Strohbuecker, D. Christie, N. Dai, S. Guan, J. M. Foster, I. R. Corrêa, M. Loose, J. E. Dixon, V. Sottile, A. D. Johnson and A. Ruzov, Cell Rep., 2014, 7, 1353-1361.

27 M. Eleftheriou, A. J. Pascual, L. M. Wheldon, C. Perry, A. Abakir, A. Arora, A. D. Johnson, D. T. Auer, I. O. Ellis, S. Madhusudan and A. Ruzov, Clin. Epigenet., 2015, 7, 88.

28 N. A. Desai and V. Shankar, FEMS Microbiol. Rev., 2003, 26, 457-491.

29 M. Nestle and W. K. Roberts, J. Biol. Chem., 1969, 244, 52195225.

30 C.-X. Song, K. E. Szulwach, Q. Dai, Y. Fu, S.-Q. Mao, L. Lin, C. Street, Y. Li, M. Poidevin, H. Wu, J. Gao, P. Liu, L. Li, G.-L. Xu, P. Jin and C. He, Cell, 2013, 153, 678-691.

31 L. Shen, H. Wu, D. Diep, S. Yamaguchi, A. C. D'Alessio, H. L. Fung, K. Zhang and Y. Zhang, Cell, 2013, 153, 692-706.

32 G. Zhang, H. Huang, D. Liu, Y. Cheng, X. Liu, W. Zhang, R. Yin, D. Zhang, P. Zhang, J. Liu, C. Li, B. Liu, Y. Luo, Y. Zhu, N. Zhang, S. He, C. He, H. Wang and D. Chen, Cell, 2015, 161, 893-906.

33 B. Yao, Y. Cheng, Z. Wang, Y. Li, L. Chen, L. Huang, W. Zhang, D. Chen, H. Wu, B. Tang and P. Jin, Nat. Commun., 2017, 8, 1122.

34 Q. Xie, T. P. Wu, R. C. Gimple, Z. Li, B. C. Prager, Q. Wu, Y. Yu, P. Wang, Y. Wang, D. U. Gorkin, C. Zhang, A. V. Dowiak, K. Lin, C. Zeng, Y. Sui, L. J. Y. Kim, T. E. Miller, L. Jiang, C. H. Lee, Z. Huang, X. Fang, K. Zhai, S. C. Mack, M. Sander, S. Bao, A. E. Kerstetter-Fogle, A. E. Sloan, A. Z. Xiao and J. N. Rich, Cell, 2018, 175, 12281243. 